http://jmscr.igmpublication.org/home/ ISSN (e)-2347-176x ISSN (p) 2455-0450 crossref DOI: https://dx.doi.org/10.18535/jmscr/v8i4.92

\title{
HRCT Chest Findings in Patients with Rheumatoid Arthritis Associated - Interstitial Lung Disease (RA-ILD)
}

\author{
Authors \\ Areca Wangnoo', Pankaj Banotra', Mohit Sharma', Annil Mahajan² \\ ${ }^{1}$ Residents, Department of General Medicine, Government Medical College, Jammu \\ ${ }^{2}$ Professor \& HOD, Department of General Medicine, Government Medical College, Jammu \\ *Corresponding Author \\ Areca Wangnoo
}

\begin{abstract}
Rheumatoid arthritis is a chronic inflammatory systemic disease with a number of extra- articular manifestations including lung disease. Our purpose of the study was to assess the HRCT findings in patients with rheumatoid arthritis associated lung diseases (RA-ILD).

Materials and Methods: A cross sectional study was conducted ona total of 36 patients of Rheumatoid arthritis associated interstitial lung disease (RA-ILD). Patients were evaluated by physiological (pulmonary function test) and radiological methods (chest X-ray, HRCT chest). Chi-square test was used for comparison of categorical variables. A $p$ value of less than 0.05 was considered statistically significant

Results: UIP was the most common ILD seen in RA in our study. Chest X Ray showed reticulonodular pattern in $39.3 \%$ of patients, prominent vascular makings in $7.1 \%$ of patients and bilateral lower zone haziness in $32.1 \%$ of patients. PFT with restrictive pattern was seen in $50 \%$ of patients and obstructive pattern was seen in $7.1 \%$ of patients. On HRCT, reticulations were present in $35.7 \%$ of patients: honey combing was present in 53.6\% of patients, ground glass opacities in $42.9 \%$, pleural thickening in $10.7 \%$, pleural effusion in $7.1 \%$, pulmonary vascular prominence in $7.1 \%$, rheumatoid nodules in $7.1 \%$ and bronchiectasis in $7.1 \%$.

Conclusion: In the present study, UIP is the most common ILD. Honey combing and ground glass opacities most common finding on HRCT in these patients. As the duration of illness increases, need for screening for pulmonary involvement with Chest Xray, PFTs and HRCT is to be emphasized along with periodic chest examination.

Keywords: Pulmonary, Rheumatoid Arthritis, Interstitial lung diseases, RA-ILD.
\end{abstract}

\section{Introduction}

Rheumatoid arthritis affects $\sim 1 \%$ of the population in developed countries. The incidence and prevalence of rheumatoid arthritis in developing countries is thought to be lower, but is difficult to quantify. ${ }^{(1,2)}$ Although joint disease is the main presentation, there are a number of extraarticular manifestations including subcutaneous nodule formation, vasculitis, inflammatory eye disease and lung disease. ${ }^{(3,4)}$ Of these manifestations, lung disease is a major contributor to morbidity and mortality. 
ILD is the most common pulmonary manifestation of rheumatoid arthritis lung disease. ${ }^{(5)}$ Most of these patients have changes consistent with ILD on either chest radiograph, High-resolution computed tomography (HRCT), pulmonary function testing (PFT), bronchoalveolar lavage (BAL).Of these patients, $76 \%$ had clinically silent disease. ${ }^{(6)}$ It is currently estimated that $\sim 30 \%$ of patients with rheumatoid arthritis have subclinical ILD noted on HRCT scans. ${ }^{(5)}$

\section{Epidemiology/Risk Factors}

Although rheumatoid arthritis is more common in females, rheumatoid arthritis associated-ILD (RAILD) occurs more frequently in males, with a male to female ratio as high as $2: 1$ in some studies. ${ }^{(7,8)}$ Onset of lung disease typically occurs in the fifth to sixth decade of life. ${ }^{(9)}$ Age has consistently been shown to be a risk factor for the development of ILD. ${ }^{(10)}$ Another major risk factor is a history of smoking, with one study finding an odds ratio of 3.8 for those who smoked $>25$ pack-years. ${ }^{(11)}$ High levels of rheumatoid factor are a known risk factor involving formation of circulating immune complexes. $^{(12)}$

\section{Pathogenesis}

The mechanism of pulmonary fibrosis occurring in ILD is not well understood. Patients with rheumatoid arthritis typically have circulating autoantibodies, the most common being rheumatoid factor and anti-cyclic citrullinated peptide (CCP). ${ }^{(13)}$ Anti-CCP antibodies have also been associated with the development of airway disease. $^{(14)}$

Cigarette smoking may play a role in inducing antibody formation and has been linked to higher titres of rheumatoid factor. (11) Smoking may promote citrullination of lung proteins, thus leading to the development of anti-CCP antibodies.

\section{Pulmonary Function Tests}

The majority of patients with RA-ILD will have a restrictive pattern on PFTs, with or without decreased diffusing capacity of the lung for carbon monoxide (DLCO) and hypoxemia. (7) Airflow obstruction may coexist and be seen in patients manifesting airway involvement, i.e. bronchiolitis obliterans.

\section{Imaging}

In UIP, HRCT scans show subpleural, basal predominant, reticular abnormalities with honeycombing, and traction bronchiectasis but a relative absence of ground-glass opacities. ${ }^{(15)}$ NSIP is the second most common pattern, occurring in $\sim 11-32 \%$ of patients. NSIP is characterised by basilar predominant ground-glass opacities and absence of honeycombing. Additional patterns less commonly seen in rheumatoid arthritis include other patterns of interstitial pneumonia, including organising pneumonia, diffuse alveolar damage (DAD), lymphocytic interstitial pneumonia (LIP) and desquamative interstitial pneumonia (DIP)-like patterns. ${ }^{(16)}$

\section{Prognosis}

ILD is second only to cardiac disease as a cause of mortality in rheumatoid arthritis ${ }^{(7,8)}$ The mean survival for RA-ILD overall has been estimated at 2.6 years from time of diagnosis compared to 9.9 years for rheumatoid arthritis patients without lung involvement; however, this probably reflects the predominance of the UIP pattern. ${ }^{(9)}$

\section{Methodology}

A cross sectional study conducted in a tertiary centre after obtaining ethical clearance during a period of 1 year from Nov 2017 to Nov 2018. A total of 36 patients of Rheumatoid arthritis associated lung diseases of either sex having age $>21$ years who met the ACR EULAR (2010) criteria for RA were included. ${ }^{(1)}$ Patients with history of cardiopulmonary disorder, collagen vascular disease (SLE, scleroderma) ,viral infection (hepatitis B \& C, HIV), tuberculosis and inhalational exposure / occupational lung disease (asbestos, silica) were excluded.

Patients were examined clinically for respiratory signs and symptoms. Patients were further evaluated for pulmonary manifestations by physiological (pulmonary function test) and radiological methods (chest X-ray, HRCT chest). 
In patients with clinical suspicion of tuberculosis sputum for AFB was done for exclusion of pulmonary tuberculosis. Patients with evidence of pulmonary fibrosis on HRCT chest were further investigated for $\mathrm{HBsAg}$, anti-HCV, HIV to rule out pulmonary fibrosis secondary to viral infections. Majority of our patients were on DMARDs and were not excluded from our study.

\section{Statistical Analysis}

Continuous variables were expressed as Mean \pm SD and categorical variables were summarized as percentages. Chi-square test was used for comparison of categorical variables. Graphically the data was presented by bar and pie diagrams. A $\mathrm{p}$ value of less than 0.05 was considered statistically significant.

\section{Results}

Age distribution of RA-ILD patients shows that $7.1 \%$ of patients were in $31-40$ years of age group, $25 \%$ of patients were in 41-50 years of age group, $39.3 \%$ of patients were in 51-60 years of age group and $28.6 \%$ of patients were in $>60$ years of age. (Figure 1)

Chest X Ray was normal in $28.6 \%$ of patients, reticulonodular pattern in $39.3 \%$ of patients, prominent vascular makings in $7.1 \%$ of patients and bilateral lower zone haziness in $32.1 \%$ of patients. (Table 1)

PFT was normal in $28.6 \%$ of patients, restrictive pattern was seen in $50 \%$ of patients, obstructive pattern was seen in $7.1 \%$ of patients and $14.3 \%$ of patients were not cooperative for PFT. (Figure 2)

As per HRCT Pattern. Reticulations were present in $35.7 \%$ of patients: honey combing was present in $53.6 \%$ of patients, ground glass opacities in $42.9 \%$, pleural thickening in $10.7 \%$, pleural effusion in $7.1 \%$, pulmonary vascular prominence in $7.1 \%$, rheumatoid nodules in $7.1 \%$ and bronchiectasis in $7.1 \%$.(Figure 3 )

Among the patients with RA-ILD, $72.73 \%$ of males had UIP while $47.06 \%$ of females had UIP and $27.27 \%$ of males had NSIP while $52.94 \%$ of females had NSIP. (Figure 4)

Figure 1 Age Distribution of RA-ILD Patients

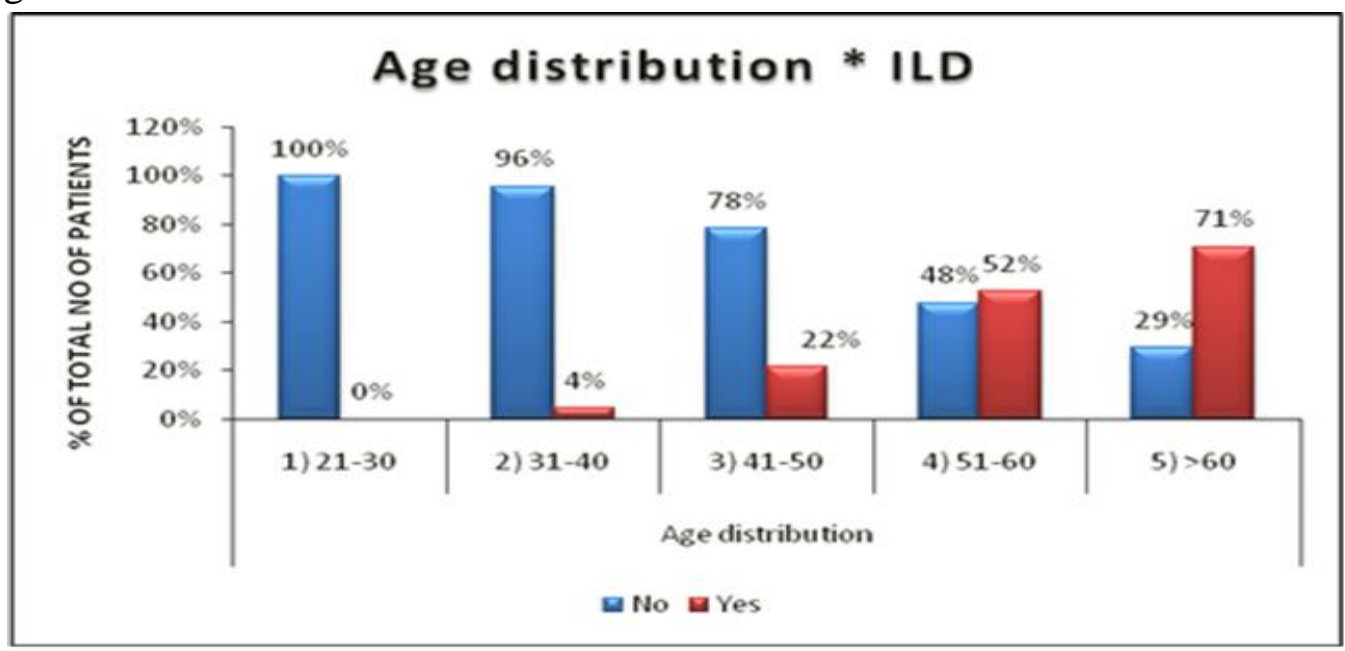

Table 1: Distribution of RA-ILD patients as per chest X-Ray findings

\begin{tabular}{|l|c|c|}
\hline Chest X-Ray Findings & No. of patients & Percentage \\
\hline Normal & 8 & $28.6 \%$ \\
\hline Reticulonodular Pattern & 11 & $39.3 \%$ \\
\hline Prominent Vascular Markings & 2 & $7.1 \%$ \\
\hline Bilateral Lower zone Haziness & 9 & $32.1 \%$ \\
\hline
\end{tabular}




\section{JMSCR Vol||08||Issue||04||Page 523-529||April}

Figure 2: Distribution of RA-ILD patients as per PFT findings

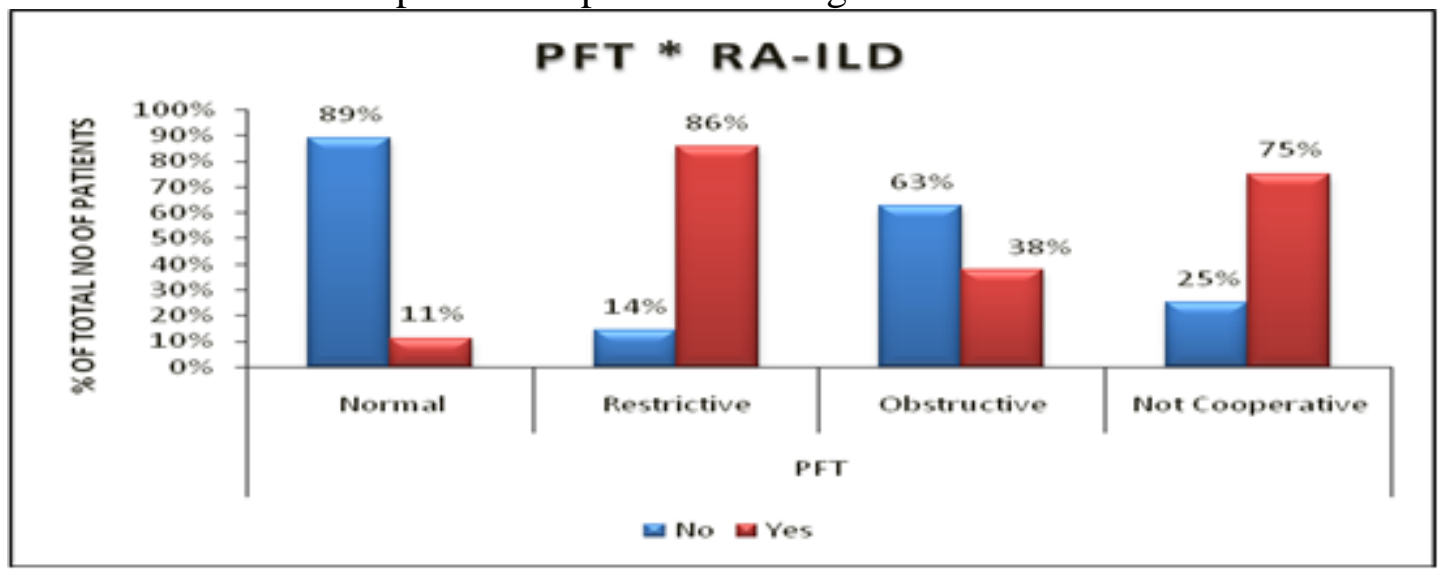

Figure 3: Distribution of RA-ILD patients as per HRCT findings

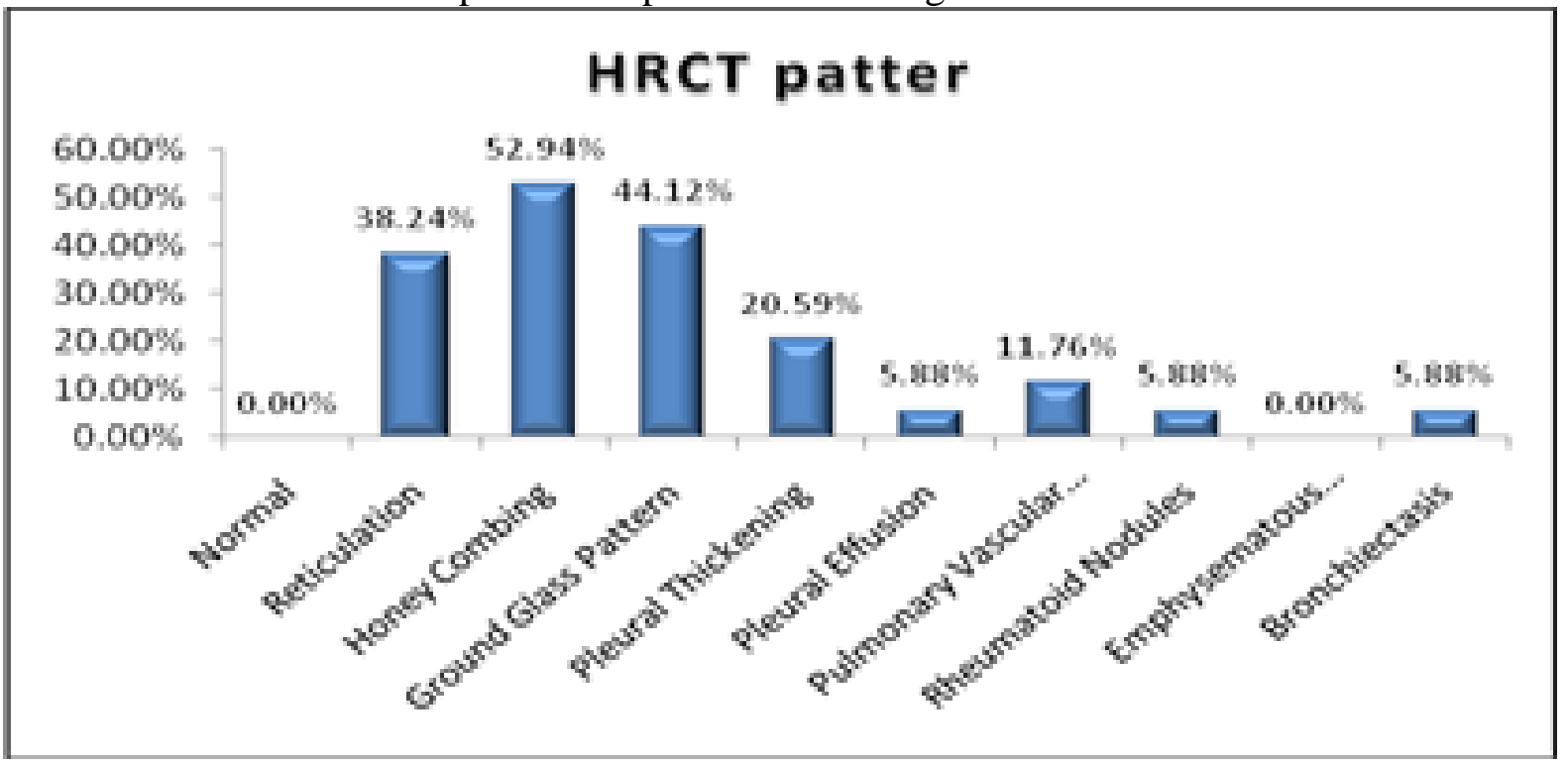

Figure 4: Distribution of RA-ILD patients according to gender and pattern of involvement

\section{Showing RA-ILD patients as per gender}

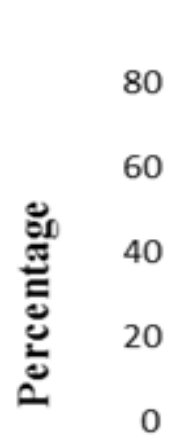

72.73

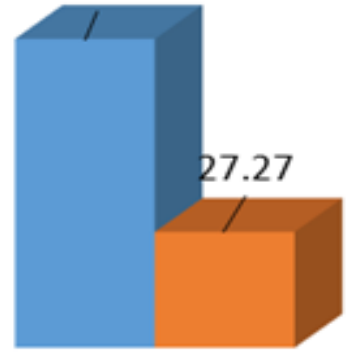

Male

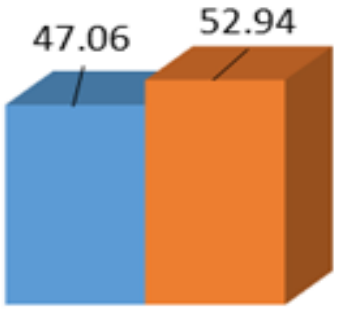

Female

\section{Gender}




\section{Discussion}

Rheumatoid arthritis (RA) is an autoimmune disease affecting $0.5-1 \%$ of the world population. Being a multisystem disorder, RA virtually affects every organ system of the body and one of the major causes of mortality in patients of RA is lung involvement, cardiovascular involvement being most important cause.

The percentage of patients with lung involvement in age group > 60 years dropped to $28.6 \%$ as compared to $39.3 \%$ in age of $51-60$ years. The lesser proportion of patients in age more than 60 years can be attributed to higher mortality of RA in this age group, but further studies are needed to validate our assumption. The results in our study were in comparison with the study conducted by Kelly et al. (2014)who demonstrated that median age at diagnosis of RA was 56 years (range 2376). ${ }^{(13)}$ Similarly Assayag D et al. (2014), studies mean age ranged 55 to 69 years in RA-ILD. ${ }^{(10)}$ Our findings were also consistent with study done by Bilgici A et al. (2005). ${ }^{(17)}$

Chest $\mathrm{X}$ ray being the primary imaging modality for screening of lung pathology revealed abnormality in about three quarters of patients with reticulonodular pattern and lower lobe haziness in $39.3 \%$ and $32.1 \%$ of patients respectively. Similar findings were as demonstrated by N. Fatima et al. (2013) who found that the predominant finding on chest X-ray was reticulonodular pattern. ${ }^{(18)}$

Sixteen $(57.1 \%)$ patients had UIP with reticulation with or without honeycombing on HRCT and 12 (42.9\%) patients had NSIP with predominant ground glass opacities on HRCT. UIP was the most common ILD seen in RA in our study. In the study done by DeLauretis et al (2011), NSIP was the most common pattern in all CTDs, except for RA which is characterized by a higher frequency of UIP. ${ }^{(8)}$ Similarly, Kelly et al (2014) also studied that UIP was the most common subtype on HRCT. ${ }^{(13)}$ UIP was predominantly seen in $65 \%$ followed by NSIP in $24 \%$. In our study, second most common pattern was NSIP; Similar results were seen by Lee HK et al. (2005) ${ }^{(21)}$ UIP was more common in males compared to NSIP as reported by similar studies. ${ }^{(18-21)}$

Pulmonary function test was abnormal in 16 (57.1\%) patients with predominant restrictive pattern in $14(50 \%)$ patients. In the study done by N. Fatima et al. (2013), 27 patients (43\%) had abnormal PFT with restrictive pattern in $18(29 \%)$ and obstructive pattern in $5(8 \%)$ of patients. ${ }^{(18)} \mathrm{In}$ similar studies, restrictive pattern was seen in $52.9 \%$ and obstructive pattern in $11.8 \%$ of patients. ${ }^{(22,23)}$

Stressing upon the fact, that, early recognition and treatment of RA-ILD can halt or modify lung involvement in RA. These findings on the imaging modalities and physiological testing can be used for the early diagnosis of the entity.

\section{Conclusion}

In the present study, UIP is the most common ILD. Honey combing and ground glass opacities most common finding on HRCT in these patients. As the duration of illness increases, need for screening for pulmonary involvement with Chest $\mathrm{X}$ ray, PFTs and HRCT is to be emphasized along with periodic chest examination.

\section{References}

1 Aletaha D, Neogi T, Silman AJ, Funovits J, Felson DT, Bingham CO et al. Rheumatoid arthritis classification criteria: an American College of Rheumatology / European League Against Rheumatism collaborative initiative. Ann Rheum Dis 2010; 69: 1580-8

2 Richman N, Yazdany J, Graf J, Chernitskiy V, and Imboden J.Extraarticular manifestations of rheumatoid arthritis in a multiethnic cohort of predominantly Hispanic and Asian patients. Medicine 2013; 92: 92-7

3 Hamblin M. and Horton M. Rheumatoid arthritis-associated interstitial lung disease: diagnostic dilemma. Pulmon Med 2011: 112 
4 Chan E, Chapman K. and Kelly C. interstitial lung disease in rheumatoid arthritis; a review. Arthritis Research Topical Reviews Series 2013; 7: 1-4.

5 Doyle TJ, Lee JS, Dellaripa PF, Lederer JA, Matteson EL, Fischer A, et al. A roadmap to promote clinical and translational research in rheumatoid arthritis-associated interstitial lung disease. Chest 2014; 145: 454-63

6 Gabbay L, Tarala R, Will R, Carroll G, Adler B, Cameron D. et al. Interstitial limy disease in new onset rheumatoid arthritis. American Journal of Respiratory and Critical Care Medicine 1997; $156(2$ (Part 1)): 528-36

7 Cavagna L, Monti S, Grosso V, Boffini N,Scorletti E, CrepaldiG, et al. The multifaceted aspects of interstitial lung disease in rheumatoid arthritis. Biomed Res Int 2013; 2013: 759-60

8 De Lauretis A, Veeraraghavan $\mathbf{S}$, Renzoni E. Connective tissue diseaseassociated interstitial lung disease: how does it differ from IPF? How should the clinical approach differ? Chron Respir Dis 2011; 8:53-82

9 Bongartz T, Nannini C, MedinaVelasquez YF, Achenbach SJ, Crowson CS, Ryu JH et al. Incidence and mortality of interstitial lung disease in rheumatoid arthritis: a population-based study. Arthritis Rheum 2010 Jun;62: 1583-91

10 Assayag D, Lubin M, Lee JS, King TE, Collard HR, Ryerson CJ. Predictors of mortality in rheumatoid arthritis-related interstitial lung disease. Respirology 2014; 19: 493-500

11 Saag KG, Cerhan JR, Kolluri S, Ohashi K, Hunninghake GW, Schwartz DA. Cigarette smoking and rheumatoid arthritis severity. Ann Rheum Dis 1997; 56: 463-9

12 Turesson C, Jacobsson L, Sturfelt G, Matteson E, Mathsson L. and Ronnelid J. et al. Rheumatoid factor and antibodies to cyclic citrullinated peptides are associated with severe extra-articular manifestations in rheumatoid Arthritis. Ann Rheum Dis 2007; 66: 59-64

13 Kelly C, Saravanan V, Nisar M, Arthanari S, Woodhead F, Price-Forbes A, Dawson J, et al. Rheumatoid arthritisrelated interstitial lung disease: associations, prognostic factors and physiological and radiological characteristics - a large multicentre UK study. Rheumatology 2014; 53: 1676-82

14 Fischer A, Solomon JJ, du Bois RM, Deane KD, Olson AL, Fernandez- Perez ER, et al. Lung disease with anti-CCP antibodies but not rheumatoid arthritis or connective tissue disease Respir Mod 2012; 106: 1040-7

15 Raghu G, Collard HR, Egan JJ, Martinez FJ, Behr J, Brown KK, et al. An official ATS/ ERS/ JRS/ALAT statement: idiopathic pulmonary fibrosis: evidence-based guidelines for diagnosis and management. Am J Respir CritCare Med 2011; 183: 788-824

16 Cottin V, Cordier JF. Combined pulmonary fibrosis and emphysema in connective tissue disease. CurrOpinPulm Med 2012; 18:418-27

17 Bilgici A, Ulusoy H, Kuru O, Celenk C, Unsal M, Danaci $M$ et al. Pulmonary involvement in rheumatoid arthritis. Rheumatol Int 2005; 25: 429-35

18 Fatima N, Shameem M, Malik A, Khan PA, Shujatullah F, Ahmed S, Nabeela. A Study on the Pulmonary Manifestations of Rheumatoid Arthritis from a North Indian Town. Open Journal of Respiratory Diseases.2013; 3: 128-31

19 Kim EJ, Collard HR and King TE. Rheumatoid Arthritis-Associated Interstitial Lung Disease: The Relevance of Histopathologic and Radiographic Pattern. Chest 2009; 136: 1397-1405 
20 Dawson J, Fewins H, Desmond J, Lynch

$M$ and Graham D.Predictors of progression of HRCT diagnosed fibrosing alveolitis in patients with rheumatoid arthritis. Ann Rheum Dis 2002; 61: 517-21

21 Lee HK, Kim DS, Yoo B, Seo JB, Rho JY, Colby TV, Kitaichi M. Histopathologic pattern and clinical features of rheumatoid arthritis-associated interstitial lung disease. Chest 2005; 127: 2019-27

22 Balbir-Gurman A, Yigla M, Nahir AM, Braun-Moscovici Y. Rheumatoid pleural effusion. Semin Arthritis Rheum.2006; 35:368-378

23 Biederer J, Schnabel A, Muhle C, Gross W, Heller M, Reuter M. et al. Correlation between HRCT findings, pulmonary function tests and bronchoalveolar lavage cytology in interstitial lung disease associated with rheumatoid arthritis. Eur Radiol 2004; 14: 272-80. 